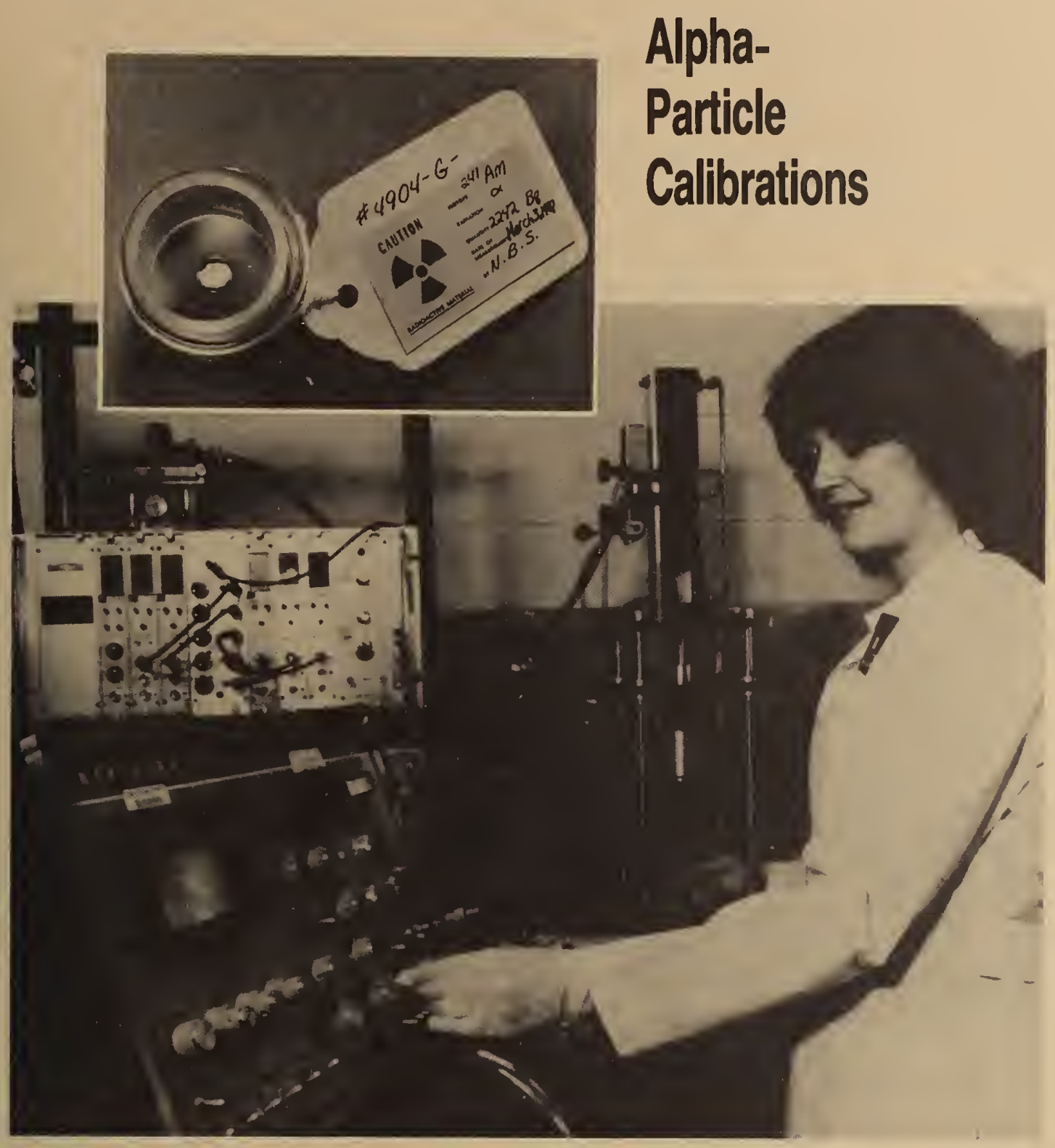

NBS

Special

Publication

250-5

J. M. Robin Hutchinson

U.S. Department of Commerce

National Bureau of Standards 


\title{
Center for Radiation Research
}

The Center for Radiation Research is a major component of the National Measurement Laboratory in the National Bureau of Standards. The Center provides the Nation with standards and measurement services for ionizing radiation and for ultraviolet, visible, and infrared radiation; coordinates and furnishes essential support to the National Measurement Support System.for ionizing radiation; conducts research in radiation related fields to develop improved radiation measurement methodology; and generates, compiles, and critically evaluates data to meet major national needs. The Center consists of five Divisions and one Group.

\section{Atomic and Plasma Radiation Division}

\section{Carries out basic theoretical and experimental research into the} spectroscopic and $r$ adiative properties of atoms and highly ionized species; develops well-defined atomic radiation sources as radiometric or wavelength standards; develops new measurement techniques and methods for spectral analysis and plasma properties; and collects, compiles, and critically evaluates spectroscopic data. The Division consists of the following Groups:
- At omic Spectroscopy

- Atomic Radiation Dat a

- Plasma Radiation

\section{Radiation Physics Division}

Provides the central national basis for the measurement of far ultraviolet, soft $x-r a y$, and electron radiation; develops and disseminates radiation standards, measurement services, and data for for these radiations; conducts theoretical and experimental research with electron, laser, ultraviolet, and soft $x-r$ ay radiation for measurement applications; determines fundamental mechanisms of electron and photon inter actions with matter; and develops advanced electron- and photon-based measurement techiques. The Division consists of the following Groups:
- Far UV Physics

- Electron Physics

- Photon Physics

\section{Radiometric Physics Division}

\author{
Provides national measurement standards and support services for ultra- \\ violet, visible, and infrared radiation; provides standards dissemination \\ and measurement quality assurance services; conducts research in optical \\ radiation, pyrometry, photometry, and quantum radiometry; and develops \\ spectroradiometric and spectrophotometric standards and calibration \\ procedures. The Division consists of the following Groups: \\ - Spectral Radionetry \\ Spectrophotometry \\ Radiometric Measurement Services
}

\section{Radiation Source and Instrumentation Division}

\section{Develops, operates, and improves major NBS radiation facilities} including the electron Linac and race track microtron; develops, designs, and builds electronic and mechanical instrumentation for radiation programs and facilities; provides national leadership in the standardization of nuc lear instrumentation; and develops new competence in radiation sources and instrumentation. The Division consists of the following Groups:

\section{lonizing Radiation Division}

Provides primary national standards, measurement services, and basic data for applications of ionizing radiation; develops new methods of chemical and physical dosimetry; conducts theoretical and experimental research on the fundamental physical and chemical interactions of ionizing radiation with matter; provides essential standards and measurement support services to the National Measurement Support Systen for Ionizing Radiation; and develops and operates radiation sources needed to provide primary radiation standards, fields, and well-characterized beams of radiation for research on radiation interactions and for development of measurement methods. The Division consists of the following office and Groups:
- Accelerator Research

- Linac Operations

- Electronic Instrument ation

- Mechanical Instrumentation

\section{Nuclear Physics Group}

Engages in forefront research in nuclear and elementary particle physics; performs highly accurate measurements and theoretical analyses which probe the structure of nuclear matter; and improves the quant it at ive understanding of physical processes that underlie measurement science.

- Office of Radiation Measurement

- Radiation Theory

- Radiation Chemistry and Chemical Dosimetry

- Neutron Measurements and Research

- Neutron Dosimetry

- Radioactivity

- X-Ray Physics

- Dos imetry 


\section{NBS MEASUREMENT SERVICES: ALPHA-PARTICLE CALIBRATIONS}

J. M. Robin Hutchinson

Center for Radiation Research

National Measurement Laboratory

National Bureau of Standards

Gaithersburg, MD 20899

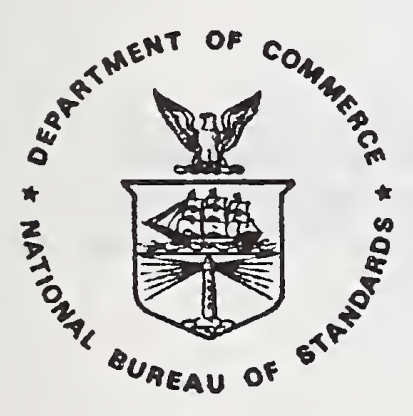

U.S. DEPARTMENT OF COMMERCE, Malcolm Baldrige, Secretary NATIONAL BUREAU OF STANDARDS, Ernest Ambler, Director Issued July 1987 
Library of Congress Catalog Card Number: 87-619849

National Bureau of Standards Special Publication 250-5

Natl. Bur. Stand. (U.S.), Spec. Publ. 250-5, 34 pages (July 1987) CODEN: XNBSAV

Commercial products - materials and instruments - are identified in this document for the sole purpose of adequately describing experimental or test procedures. In no event does such identification imply recommendation or endorsement by the National Bureau of Standards of a particular product; nor does it imply that a named material or instrument is necessarily the best available for the purpose it serves.

U.S. GOVERNMENT PRINTING OFFICE WASHINGTON: 1987 


\section{PREFACE}

The calibration and related measurement services of the National Bureau of Standards are intended to assist the makers and users of precision measuring instruments in achieving the highest possible levels of accuracy, quality, and productivity. NBS offers over 300 different calibration, special test, and measurement assurance services. These services allow customers to directly link their measurement systems to measurement systems and standards maintained by NBS. These services are offered to the public and private organizations alike. They are described in NBS Special Publication (SP) 250, NBS Calibration Services Users Guide.

The Users Guide is being supplemented by a number of special publications (designated as the "SP 250 Series") that provide a detailed description of the important features of specific NBS calibration services. These documents provide a description of the: (1) specifications for the service; (2) design philosophy and theory; (3) NBS measurement system; (4) NBS operational procedures; (5) assessment of measurement uncertainty including $r$ andom and systematic errors and an error budget; and (6) internal quality control procedures used by NBS. These documents will present more detail than can be given in an NBS calibration report, or than is generally allowed in articles in scientific journals. In the past NBS has published such information in a variety of ways. This series will help make this type of information more readily available to the user.

This document (SP 250-5), NBS Measurement Services: Alpha-Particle Calibrations, by J.M. R. Hutchinson, is the fifth to be published in this new series of special publications. It describes the calibration of alpha-particle sources submitted to NBS for calibration of either their $2 \pi$ steradian emission rate or their total activity (see test numbers $43030 \mathrm{C}$ and 430300 in the SP 250 Users Guide). Inquiries concerning the technical content of this document or the specifications for these services should be directed to the author or one of the technical contacts cited in SP 250.

The Center for Radiation Research (CRR) is in the process of publishing 21 documents in this SP 250 series, covering all of the calibration services offered by CRR. A complete listing of these documents can be found inside the back cover.

NBS would welcome suggestions on how publications such as these might be made more useful. Suggestions are also welcome concerning the need for new calibration services, special tests, and measurement assurance programs.

George A. Uriano Director

Measurement Services
Chr is E. Kuyatt

Director

Center for Radiation Research 


\section{ABSTRACT}

This document describes the alpha-particle calibration services offered by the Radioactivity Group of the National Bureau of Standards (NBS) (Scheduled Calibrations; $43030 \mathrm{C}$ and 43040C; formerly 8.2H and 8.2I). The fundamental measurement quantities are defined, the measurement approach is described (or reviewed), and the operating procedures are described from the point of view of the calibration technician or metrologist. The measurement uncertainties, and how they are estimated, are described. Methods for maintaining and assessing quality control, e.g., international comparisons, MQA programs, etc. are also briefly reviewed.

Key words: alpha particle; calibrations; counters; emission rate; radioactivity; standards 
Abstract

List of Tables ......................................... vi

List of figures $\ldots \ldots \ldots \ldots \ldots \ldots \ldots \ldots \ldots \ldots \ldots \ldots \ldots \ldots \ldots \ldots \ldots \ldots \ldots \ldots$

1. Introduction $\ldots \ldots \ldots \ldots \ldots \ldots \ldots \ldots \ldots \ldots \ldots \ldots \ldots \ldots \ldots \ldots \ldots \ldots \ldots \ldots$

2. Description of Service ............................... 1

3. Design Philosophy and Theory ........................... 2

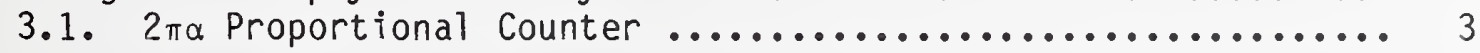

3.2. $0.8 \pi \alpha$ Counter .................................... 8

4. Description of Systems ............................... 11

$4.1 . \quad 2 \pi \alpha \ldots \ldots \ldots \ldots \ldots \ldots \ldots \ldots \ldots \ldots \ldots \ldots \ldots \ldots \ldots \ldots \ldots \ldots \ldots \ldots \ldots \ldots \ldots \ldots \ldots \ldots$

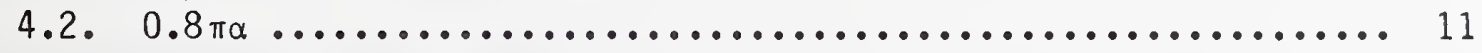

5. General Operational Procedures .......................... 12

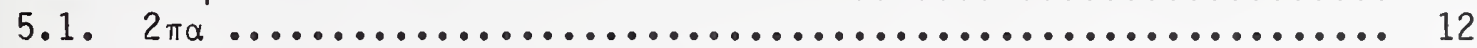

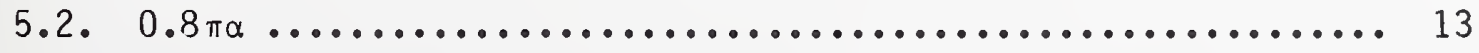

6. Step-by-Step Procedures .............................. 13

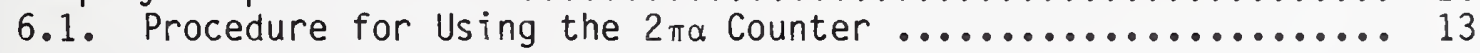

6.2. Procedure for Using the $0.8 \pi \alpha$ Defined-Solid-Angle Counter .. 15

7. Calibration Service Procedure ........................... 17

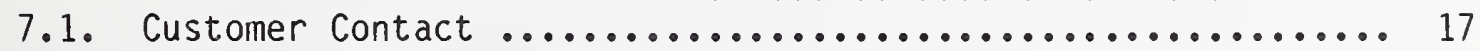

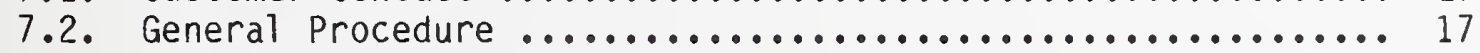

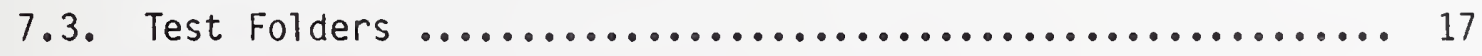

8. Uncertainty Components ................................ 18

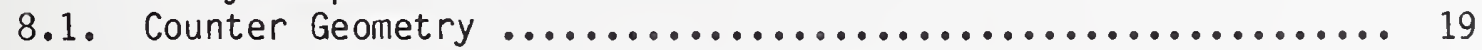

8.2. Extension and Non-Uniformity of Source ................. 20

8.3. Self-Absorption and Scattering from Source and Support ..... 20

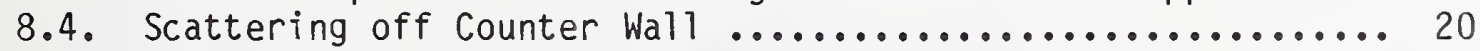

8.5. Transmission through Collimator Edge ................. 20

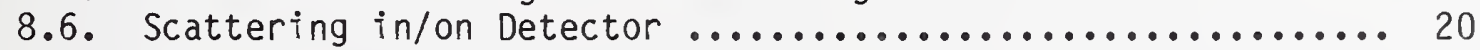

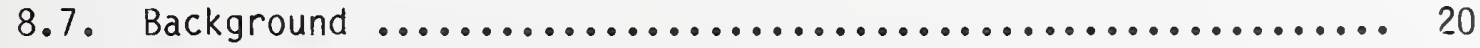

8.8. Dead-Time .................................... 20

8.9. Extrapolation to Zero Pulse Height ................... 20

8.10. Setting of $400 \mathrm{keV}$ Discrimination Level ................. 20

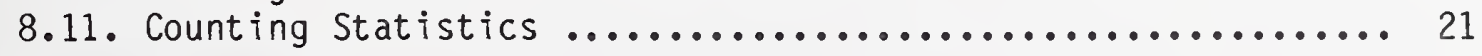

9. Qual ity Control .................................... 21

10. References ....................................... 22

11. Appendices

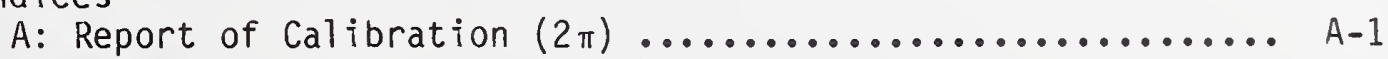

B: Report of Cal ibration $(0.8 \pi) \ldots \ldots \ldots \ldots \ldots \ldots \ldots \ldots \ldots \ldots . . . \ldots \ldots$ 
Table 1. Specifications for calibrations using the $2 \pi \alpha$ proportional counter and the $0.8 \pi \alpha$ defined solid angle counter .......... 2

Table 2. Approximate relative scintillation efficiencies of various commercially available materials at room temperature ......... 10

Table 3. Listing of count rate correction factors and typical $1 \sigma$ uncertainties for $2 \pi$ and $0.8 \pi$ measurements 


\section{LIST OF FIGURES}

Page

Fig. 1 . $2 \pi$ solid angle alpha counter ....................... 3

Fig. 2. Pulse height spectrum for $0.8 \pi$ solid angle alpha counter ...... 4

Fig. 3. Relative count rate as a function of counter voltage for $2 \pi$ solid angle alpha counter ............................ 5

Fig. 4. Relative count rate as a function of source position for $2 \pi$ solid angle alpha counter ............................ 5

Fig. 5. Ratio of $2 \pi$ counting rate to activity as a function of source

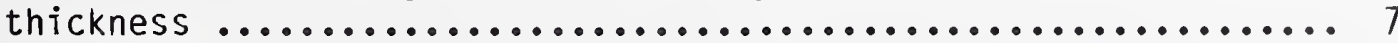

Fig. 6. Schematic of $0.8 \pi$ defined-solid-angle alpha counter $\ldots \ldots \ldots \ldots .8$

Fig. 7. Count rate versus angle of emission for $0.8 \pi$ solid angle alpha counter 

Alpha particles emitted from radioactive sources are measured at the National Bureau of Standards (NBS) in two systems, the $2 \pi$ steradian proportional counting system (denoted " $2 \pi \alpha$ " system) and the $0.8 \pi$ steradian CsI(TI) scintillation system (denoted " $0.8 \pi \alpha^{\prime \prime}$ system). The full energy of the alpha particles are absorbed in the counting gas in the first system and in the scintillator in the second system. A ("frequency") spectrum of alpha-particle counts in a counting period versus alpha-particle energy deposited in either the gas or scintillator is collected and displayed in a multichannel analyzer. Overall counting rates are determined from sums of all or parts of these spectra as discussed below.

2. Description of Service $[1]:^{1} \quad 43030 \mathrm{C}$ and $43040 \mathrm{C}$ (previously $8.2 \mathrm{H}$ and

Alpha-particle sources are submitted by outside laboratories to NBS for calibration of either their $2 \pi$ steradian emission rate or of the ir total activity, i.e., emission rate into $4 \pi$ including those alpha particles self absorbed by the source - that is, the total number of radioactive atoms that decay per unit time regardless of the fate of the resulting emissions. Emission rate is measured in alpha-particles per second detected in $2 \pi$ geometry - in this case by the $2 \pi$ proportional counter. Because the resulting pulse-height distribution is continuous down to zero energy and alpha particles cannot always be separated from pulses produced by recoiling daughters ( $100 \mathrm{keV}$ ) in the proportional counter, sometimes only pulses above an arbitrary cutoff of $400 \mathrm{keV}$ are counted and certified in the $2 \pi$ emission rate measurements. (This is discussed further in the Operational Procedures section.) Activity, $\mathrm{N}_{0}$, is measured in becquerels (Bq), the SI unit which is al so dimensionally "per second," and represents the total number of alpha particles per second produced by the purely alpha-particle emitting source. Emission rate, $N_{2 \pi}$, is measured on the NBS $2 \pi$ a-particle proportional counter and activity is usually measured with the $0.8 \pi \alpha$-particle counter, both of which are described in the main body of the text. Calibrations are checked by simultaneously calibrating a previously-calibrated standard source (see page 11).

Typical calibration reports for $2 \pi \alpha$-emission rate measurement and $0.8 \pi \alpha$-particle emission rate are given in Appendices $A$ and $B$.

Sources submitted by the customer to NBS for calibration must satisfy certain requirements. The source thickness must be such that more than 99.5 percent of the alpha particles emitted have an energy greater than $400 \mathrm{keV}$. Packaging for all sources must be in compliance with Department of Transportation (DOT) and Nuclear Regulatory Commission (NRC) regulations. Copies of regulations may be obtained from Operations Division, Office of Hazardous Materials, Department of Transportation, Washington, D.C. 20590. Postal regulations prohibit mailing radioactive materials which require a caution label under DOT regulations. Alpha-particle solid sources must be

${ }^{1}$ Numbers in brackets indicate 1 iterature references at the end of this document. 
supplied in special source holders such that the active area is not touched by any material. For sources measured in the $2 \pi \alpha$ counter (Cal ibration 43030C) the diameter of the source must be less than $10 \mathrm{~cm}$ and that of the active surface less than $9 \mathrm{~cm}$. For the $0.8 \pi \alpha$ counter (Calibration 43040C), the maximum diameter is only $1.6 \mathrm{~cm}$.

Further specifications for these calibration services are given in the following table. (Table 1)

Table 1. Specifications for calibrations using the $2 \pi \alpha$ proportional counter and the $0.8 \pi \alpha$ defined solid angle counter.

\begin{tabular}{|c|c|c|}
\hline & Calibration 43030C & Calibration $43040 \mathrm{C}$ \\
\hline Counting System & NBS $2 \pi \alpha$ proportional Counter & $\begin{array}{l}\text { NBS } 0.8 \pi \alpha \text { defined- } \\
\text { sol id-angle-counter }\end{array}$ \\
\hline Sources Calibrated for: & $\begin{array}{l}\text { Alpha-particle emission rate } \\
\text { into } 2 \pi \text { Steradians either } \\
\text { above } 400 \mathrm{keV} \text { or extrapol ated } \\
\text { to zero } \mathrm{keV}\left(\text { in }^{-1}\right)\end{array}$ & $\begin{array}{l}\text { Total activity } \\
\text { (in } B q \text { ) }\end{array}$ \\
\hline Nominal Uncertainty $(\sim 3 \sigma)$ & 1.5 percent & 1.5 percent \\
\hline Activity Range & $\sim\left(0.4-10^{4}\right) \mathrm{s}^{-1}$ & $\sim\left(40-10^{4}\right) \mathrm{s}^{-1}$ \\
\hline Maximum Source Diameter & $10 \mathrm{~cm}$ (9 cm active surface) & $1.6 \mathrm{~cm}$ \\
\hline
\end{tabular}

\section{Design Philosophy and Theory}

The $2 \pi \alpha$-proportional counter [2] is used because it records alpha particles with little interference from emitted beta particles or gamma rays. In the proportional counter, all alpha particles leaving the source into the forward hemisphere ionize atoms in the counting gas, with the number of ions produced proportional to the a-particle energy deposited. The electrons released in the ionization are accelerated in an electric field toward a collecting electrode, multiplying their number by impact ionization. The resulting electrical pulse is electronically amplified, and sorted as to pulse height. The fact that the source is "internal" (inside the counter) allows all emitted particles to be recorded without absorption by possible counter casings. (For further discussion of proportional counters see NCRP 58 [3].)

The advantage of this detection system is that sources up to $10 \mathrm{~cm}$ in diameter can be measured; however, because of the high detection efficiency and count rate limitations in the electronics, the measurements are 1 imited to sources with activities of less than $20,000 \mathrm{~Bq}$. At the lower end, count rates should be greater than 10 times background which is on the order of $0.06 \mathrm{~s}^{-1}$. 


\section{1. $2 \pi \alpha$ Proportional Counter ${ }^{2}$}

The calibration of alpha-particle sources started at the National Bureau of Standards (NBS) in the early 1950's [5]. The alpha-particle detector used consisted of a 12-cm-diameter hemispherical gas-flow proportional counter as shown in Fig. 1. This counter has been in use constantly since that time and is still much used today. Such $2 \pi$ counters are extremely versatile, and it may still be true today that, if one were limited to a single detector, the $2 \pi$ gas-flow proportional counter would be the detector of choice. Because these counters are so versatile and so widely used, I would like to make the following observations and suggestions about their use as accurate alphaparticle detectors.

\section{I2 CENTIMETER DIAMETER PROPORTIONAL COUNTER CHAMBER}

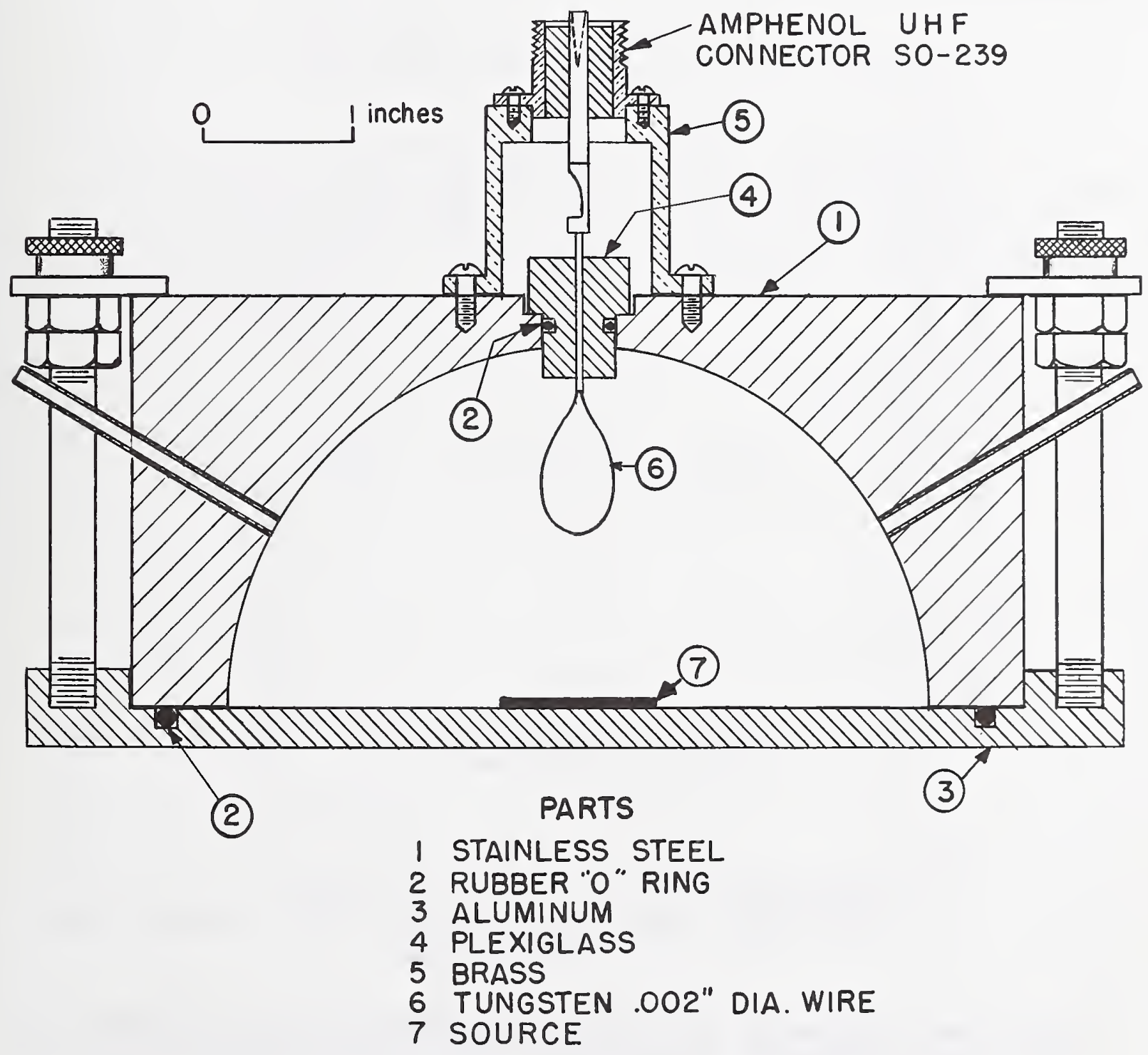

Fig. $1.2 \pi$ solid angle alpha counter

2Excerpted from Lucas [4]. 
Extrapolation to Zero Pulse Height - Regardless of the type of detection system used, an accurate determination of the total alpha-particle count rate requires that the alpha-particle pulse-height spectrum be recorded and extrapol ated to zero pulse height, as shown in Fig. 2. The high count rate at low channel numbers is primarily due to system noise. At NBS we generally fit to a second-order polynomial, al though a simple first-order polynomial (straightline extrapolation) is of ten adequate. When the pulse-height spectrum is extrapolated to zero pulse-height in this way, the total count rate remains almost constant despite a large change in the system gain, whereas the count rate above a fixed discrimination level varies significantly with the same change in the system gain. The effect of using an extrapolation-to-zero pulse height is demonstrated in Fig. 3 in terms of a plot of relative count rate versus counter voltage and in Fig. 4 in terms of a plot of relative count rate versus point-source position.

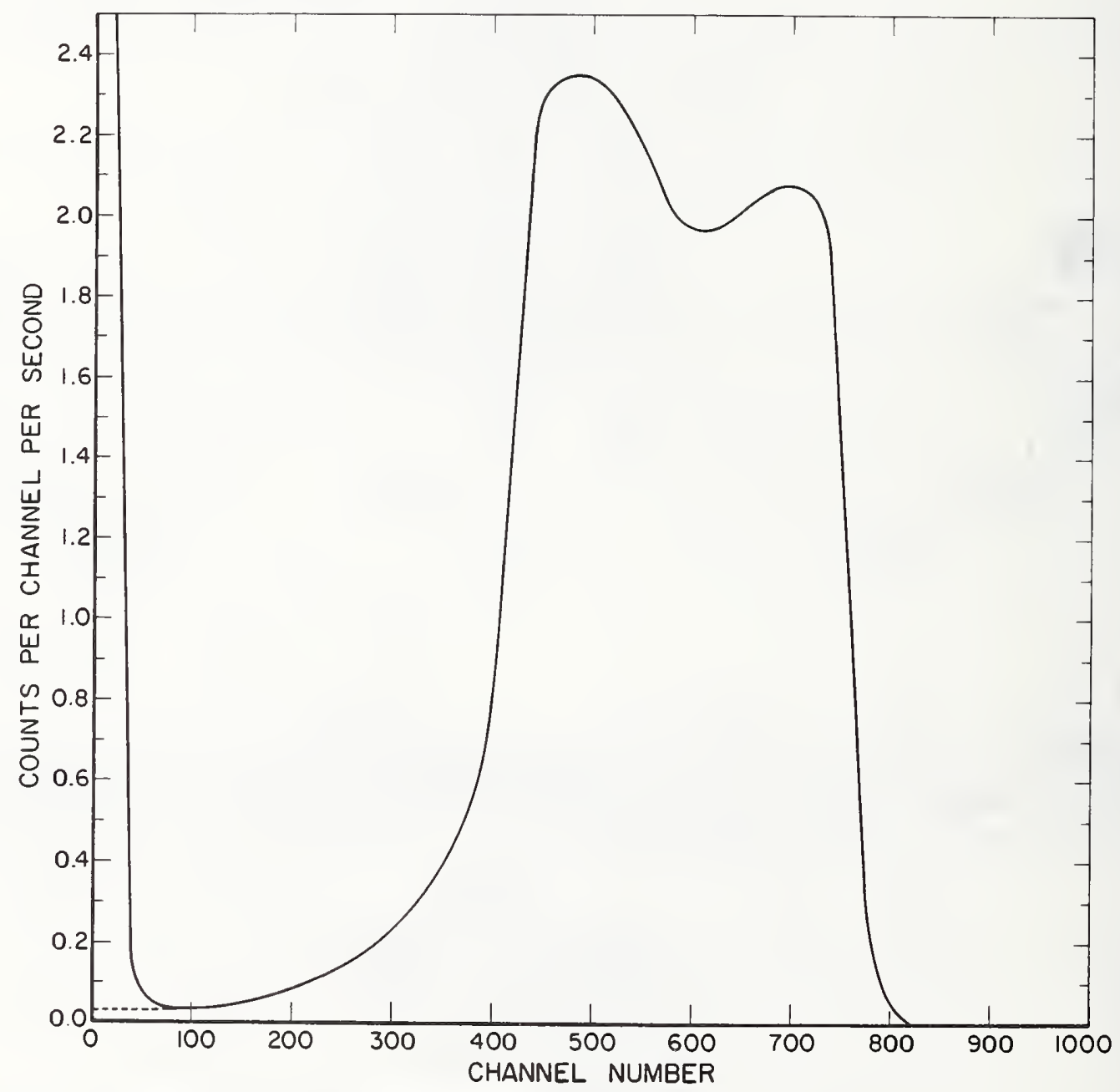

Fig. 2. The pulse-height spectrum from a sample of $239 \mathrm{Pu}$ in the NBS $0.8 \pi$ defined-geometry counter, showing the extrapolation to zero pulse height. 


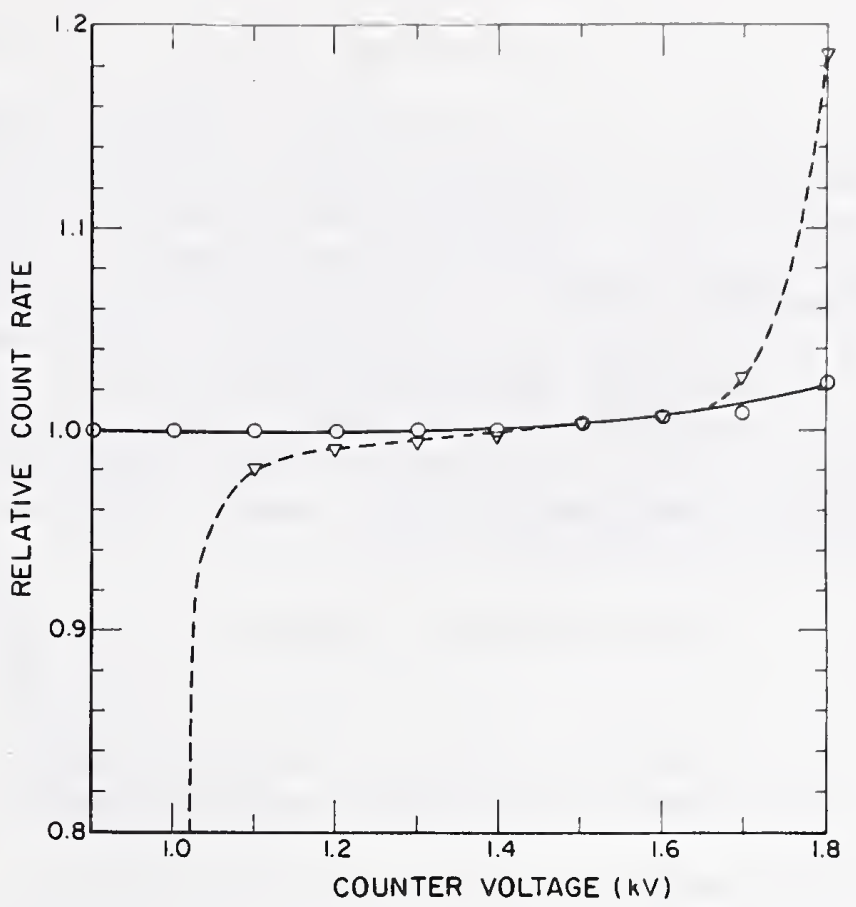

Fig. 3. Relative count rate versus counter voltage for the NBS $2 \pi \alpha$ proportional counter (see Fig. 1). An $241 \mathrm{Am}$ point source was located in the center of the chamber. The counting gas was P-10 at atmospheric pressure. The solid line is the count rate extrapolated to zero pulse height. The dashed line is the count rate above a fixed discrimination level.

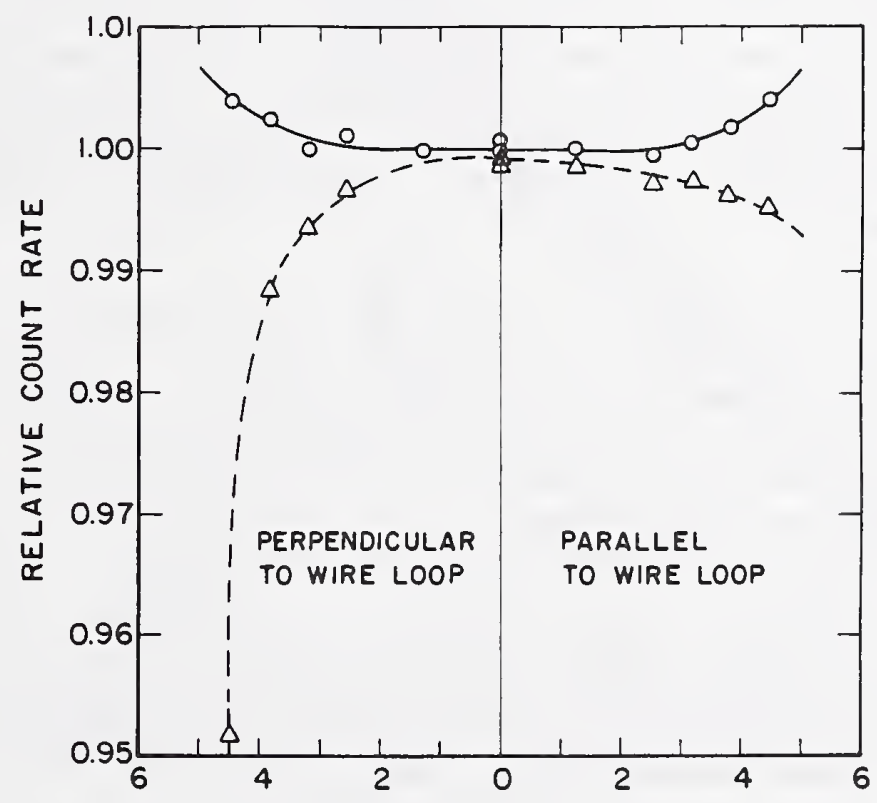

Fig. 4. Relative count rate versus position for an ${ }^{241} \mathrm{Am}$ point source in the NBS $2 \pi \alpha$ proportional counter (see Fig. 1). The counter voltage was $1400 \mathrm{~V}$. The counting gas was P-10 at atmospheric pressure. The solid line is the count rate extrapolated to zero pulse height. The dashed line is the count rate above a fixed discrimination level. 
Maximum Source Size - For uniformly high detection efficiency $(1.000 \pm$

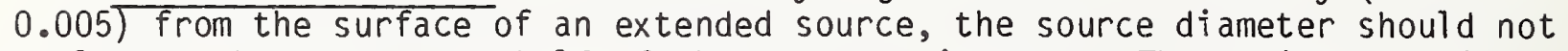
be larger than about one half of the counter diameter. The maximum permissible source size using this criterion depends upon the electric field distribution within the counter (especially the shape and position of the anode wire loop) and upon the composition of the counting gas (for example, it is larger for $P-10$ than for methane [6]) and can be determined for any given counter by plotting the count rate versus the position of a point source. Figure 4 shows such data for our $2 \pi \alpha$ counter at NBS under normal operating conditions ( 1 atm of $\mathrm{P}-10 \mathrm{gas}, 1400 \mathrm{~V})$. Note the difference when the pulse-height spectrum is extrapolated to zero pulse height.

\section{purposes:}

Counting Gas - In a proportional counter the counting gas serves two

1. It provides a medium in which an alpha particle can dissipate its kinetic energy to form free electrons and ionized atoms or molecules.

2. It provides a medium in which the free electrons so formed can be accelerated in the presence of an electric field to produce additional ionization (that is, electron multiplication and hence amplification or "gas gain").

Methane and $\mathrm{P}-10$ (90 percent argon, 10 percent methane) are the gases most often used for gas-flow proportional counters. The gas of choice in any given system or for any given application depends upon a number of factors, including cost, availability, purity, and background count rate. There are also other considerations. A much higher electric field ( that is, a much higher anode voltage) is required in methane than in P-10 for the same average electron multiplication, and the electron multiplication in methane is less affected by the presence of small concentrations of electronegative gas impurities, such as $\mathrm{O}_{2}$ and $\mathrm{H}_{2} \mathrm{O}$. However, if the pulse-height spectrum is extrapolated to zero pulse height, the effect of the change in system gain due to the presence of impurities in the counting gas will be minimal, even with P-10.

Scattering - For reasons of stability and convenience, an alpha-particle source is commonly mounted on a flat metal backing. When such a source is measured in a detector having $2 \pi$ geometry, the $2 \pi$ counting rate, $C_{2 \pi}$, is generally not one half of the activity, $N_{0}$, because some of the alpha particles initially emitted downward are backscattered into the sensitive volume of the detector, while some of the alpha particles initially emitted upward are scattered or absorbed in the source or both. As a result, the measured $\mathrm{C}_{2 \pi} / \mathrm{N}_{0}$ ratio can vary significantly from 0.50 . This is shown in Fig. 5, which is from the latest and most comprehensive [7] of a number of papers dealing with this subject. The unit-less parameter d shown in Fig. 5 is the thickness of the source material expressed as a fraction of the alphaparticle range in the same material. Note that, even for a weightless source, the correction can be very significant. Although the range in the source material is often poorly known, it can be calculated from $C_{2 \pi} / N_{0}$ measurements on a few thick $(d \geqslant 0.2)$ sources using the equations given in Lucas [8]. 


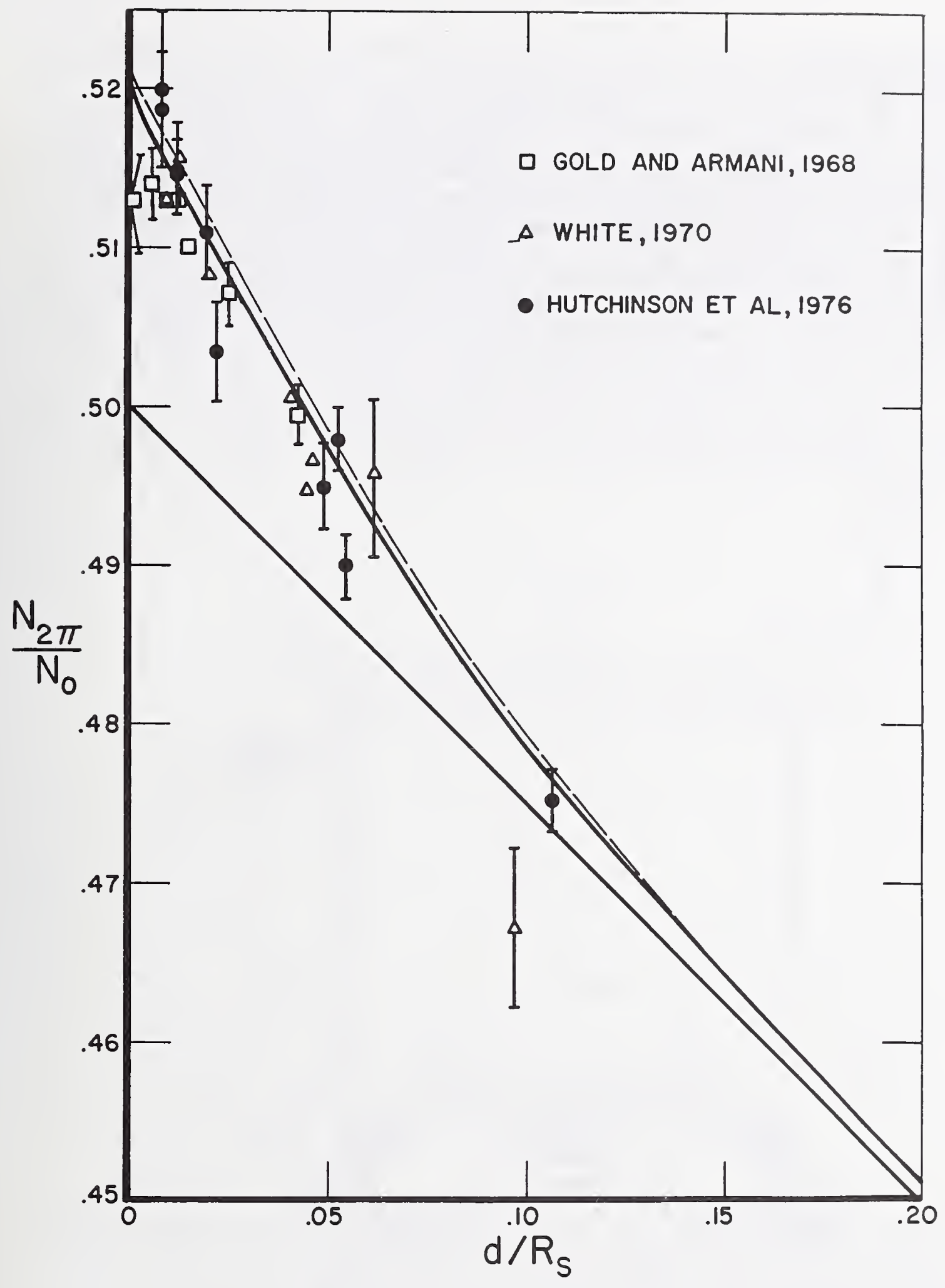

Fig. 5. Calculated and experimental values of $\mathrm{C}_{2 \pi} / \mathrm{N}_{0}$ as a function of source thickness, $d$, expressed as a fraction of the alpha-particle range in the same material $\left(\mathrm{UO}_{2}\right.$ and $\left.\mathrm{U}_{3} \mathrm{O}_{8}\right)$. See Ref. 1 for complete details. 


\section{2. $0.8 \pi \alpha$ Counter}

The $0.8 \pi \alpha$ counter, the so-called Robinson counter $[9,10]$, after the designer of the instrument, is a CSI(Tl) scintillation counter, with defined solid angle, and a three dimensional central baffle (Fig. 6). Alpha particles striking the scintillator produce light flashes proportional to the energy imparted. These flashes are transformed to electrical pulses and amplified for pulse-height analysis. The baffle is designed such that the detection efficiency is insensitive to positional changes in the source with respect to the detector. As shown in [9], a $10 \mathrm{~mm}$ vertical or horizontal displacement of the source results in a count rate change on the order of 0.1 percent. This detector should not be used with sources with diameters greater than $1.6 \mathrm{~cm}$. However, since the efficiency is approximately 40 percent of that of the $2 \pi$ counter, maximum source activities can be correspondingly greater. Unfortunately, the background is significantly higher than that in the $2 \pi$ counter and, therefore, the minimum activity sources are significantly higher $\sim$ on the order of $40 \mathrm{~Bq}$.

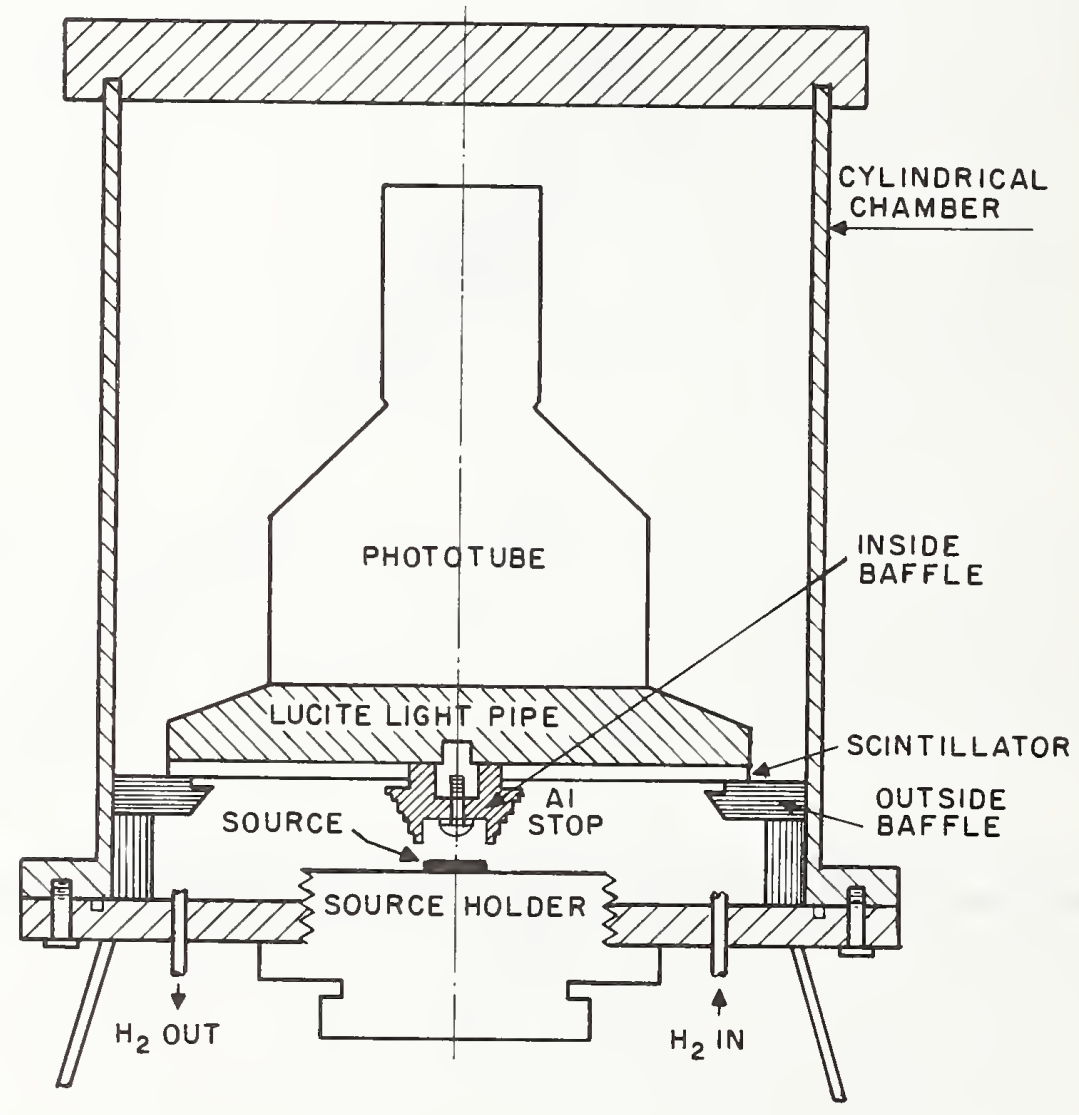

Fig. 6. Schematic of $0.8 \pi$ defined-solid-angle alpha counter. 
In about 1960 an experimental investigation ${ }^{2}$ of the energy and angular distributions of the emitted and scattered alpha particles was carried out at NBS by Walker [2]. Her results for all emitted alpha particles at various angles are shown in Fig. 7. Backscattered alpha particles are all emitted within about $20^{\circ}$ of the $\mathrm{plane}$ of the source $\left(70^{\circ}\right.$ to $90^{\circ}$ in Fig. 6). Therefore if the solid angle subtended by the detector is such as to exclude all alpha particles emitted within $20^{\circ}$ or more of the plane of the source, then the scattering correction, and the uncertainty associated with it, is eliminated. The slight slope in the central portion of the curve was apparently due to the center of rotation of the detector not being coincident with the source. Figure 7 al so shows the angles subtended by several of the defined-geometry counters now in use at NBS for the standardization of alpha-particle sources.

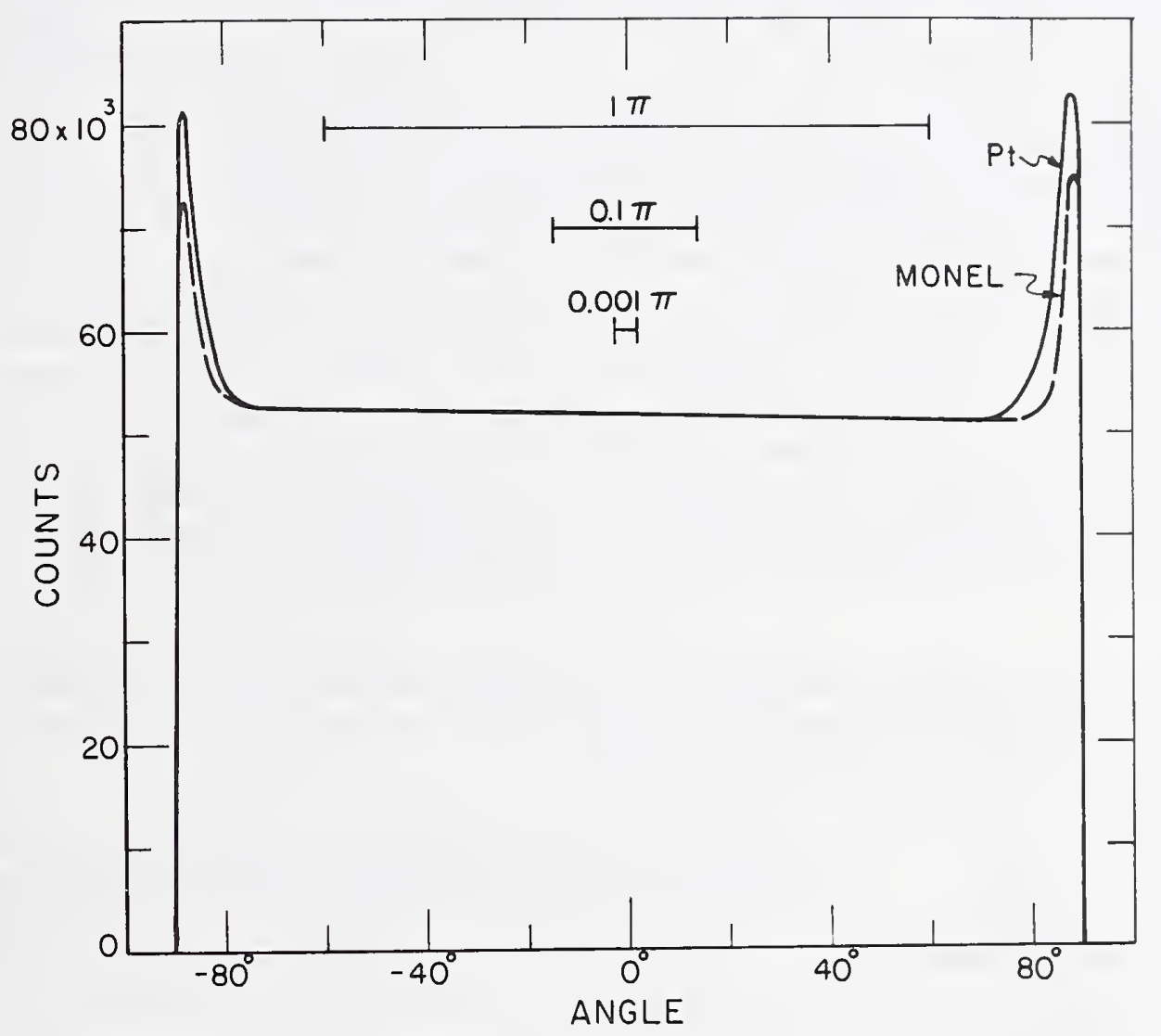

Fig. 7. Count rate versus angle of emission for alpha particles emitted by 210 po that had been deposited on the surfaces of platinum and monel disks. ( 0 is perpendicular to the surface of the disk.) See Ref. 2 for complete details. Also shown are the angles subtended by the detectors in several of the defined-geometry counters in use at NBS.

2Excerpted from Lucas [4]. 
Several defined-geometry counters have been described in the literature [9-12]. One problem that arises in the use of such counters, especially those with large solid angles, is that the geometry is very dependent upon the position of the source in the counter. A very clever design for a highgeometry counter that almost eliminates such position dependence over a wide range of horizontal and vertical displacements of the source was described by Robinson [10] and is shown in Fig. 6. The inner and outer baffles together define a detection geometry that varies less than 0.2 percent in solid angle from any point within $\pm 20 \mathrm{~mm}$ horizontally and within $\pm 1 \mathrm{~mm}$ vertically of the mean center position.

To obtain the highest accuracy from a defined-geometry counter, it is desirable to minimize the energy loss and the scattering in the region between the alpha-particle source and the collimator(s) and detector. As a result most $[10,11]$, but not all [9, 12], counters of this type are operated with the chamber under vacuum and with a solid scintillator as the alpha-particle detector. A question that always arises is, "What is the detection efficiency of the solid scintillator?" Our results at NBS indicate that the alphaparticle-detection efficiencies of our commercially prepared inorganic scintillation crystals [cesium iodide (thallium) and calcium fluoride (europium)] and organic scintillation plastics are at least 0.999. The alpha-particledetection efficiencies of zinc sulfide (silver) layers are considerably more variable because this material is available only in the form of microcrystal1 ine powder that must be deposited as a thin layer (often with a binder) to form a suitable detector. Nonetheless, for carefully prepared deposits, efficiencies of 0.999 appear to be reproducibly attainable [10]. There are, however, important differences between the various solid scintillators, especialily in relative light output for alpha particles compared with beta particles and gamma rays. Table 2 lists a number of commonly used scintillators, their relative light outputs, and their $\alpha / \beta$ response ratios.

Table 2. Approximate relative scintillation efficiencies of various commercially available materials at room temperature. The relative light output of sodium iodide (thallium) per unit energy deposited by beta particles is taken as 1.00 .

\begin{tabular}{|c|c|c|c|}
\hline \multirow{2}{*}{$\begin{array}{c}\text { Solid } \\
\text { Scintillator }\end{array}$} & \multicolumn{3}{|c|}{ Relative Light Output per Unit Energy Deposited } \\
\hline & $\alpha$ & $\beta$ & $\alpha / \beta^{a}$ \\
\hline $\mathrm{ZnS}(\mathrm{Ag})$ & 2.0 & 1. & 2.0 \\
\hline $\operatorname{CsI}(\mathrm{TI})$ & 0.4 & 0.5 & 0.8 \\
\hline $\mathrm{NaI}(\mathrm{Tl})$ & 0.5 & $\equiv 1.00$ & 0.5 \\
\hline $\operatorname{CsBr}(\mathrm{T} 1)$ & 0.05 & 0.15 & 0.3 \\
\hline $\mathrm{KBr}(\mathrm{TI})$ & 0.01 & 0.04 & 0.25 \\
\hline $\mathrm{CaF}_{2}(\mathrm{Eu})$ & 0.1 & 0.4 & 0.25 \\
\hline $\operatorname{NaCl}(\mathrm{Ag})$ & 0.01 & 0.04 & 0.2 \\
\hline Organic & 0.02 & 0.25 & 0.08 \\
\hline
\end{tabular}

a For ionization detectors (gaseous or solid state) this ratio is equal to 1.0 . 
If one is counting a source that emits only alpha particles, the $\alpha / \beta$ response ratio is not of significance. Mechanical and chemical properties would be the basis on which to select a scintillator. But if the source also emits beta particles or gamma rays or both, or if these radiations constitute an important part of the background, then the $\alpha / \beta$ response ratio may be the most important parameter in the choice of a scintillator. For example, suppose that one is counting 5.5-MeV alpha particles in the presence of 500-keV conversion electrons and that both types of particles deposit their full energies in the scintillator. 3 If the scintillator is zinc sulfide (silver), the light output due to the alpha particles will be more than 20 times that due to the conversion electrons. Hence the conversion electrons may be readily discriminated against on the basis of pulse height. If the scintillator is an organic plastic, the light outputs due to the two types of particles will be the same. In this case it will not be possible to discriminate against the conversion electrons on the basis of pulse height.

\section{Description of Systems}

4.1. $2 \pi \alpha$ : The $2 \pi \alpha$ proportional counter system is pictured in Figure 1. The source is centered inside the counter and sits on the aluminum base plate. Alpha particles emitted into the sensitive volume ionize counting gas $(P-10)$ atoms which are attracted and cascade to the positively charged anode loop where they are collected. The pulse of charge is presented to a charge sensitive preamplifier after which the pulse is amplified to overload. The resulting spectrum is collected in a multichannel analyzer.

By amplifying to overload, the condition is nearly satisfied that all alpha particles, regardless of energy, will be detected in the data collection system - the multichannel analyzer. Consequently under these conditions, extrapolation to zero pulse height is more easily accomplished because the low-energy region can be examined in detail.

4.2. $0.8 \pi \alpha$ : The $0.8 \pi \alpha \operatorname{CsI}(T 1)$ scintillation "Robinson" counter is shown in Fig. 6. The source is mounted on the "source mount" and the enclosed volume between it and the scintillator is flushed with hydrogen gas to permit the alpha particles to move with minimum loss of energy. The outside baffle and the Al stop are accurately machined with tolerances on the order of $0.005 \mathrm{~cm}$ so that the detection geometry is known to approximately 0.1 percent. Light pulses are collected in the 1 ight pipe and passed into the phototube. The resulting pulses are amplified to overload as with the $2 \pi$ system and the spectrum is collected in a multichannel analyzer.

Without the inside baffle, the source geometrical factor would be sensitive to vertical positioning of the source. As explained by Robinson [10], the three dimensional central baffle is so designed that changes in the geometrical factor defined by the outside baffle due to changes in source position, are offset by equal and opposite changes in the screening of the alpha-particle beam by the central baffle. Hutchinson et al. [9] have shown

${ }^{3}$ In actual practice, one generally tries to minimize the energy deposition of the beta particles and yamma rays by using a solid scintillator that is just thick enough to stop the alpha particles. 
that for a vertical displacement of $0.4 \mathrm{~cm}$ or a horizontal displacement of $1 \mathrm{~cm}$ of the source from the central position, the change in the count rate varies by less than 0.3 percent.

A big advantage of this counter relates to the fact that multiplyscattered alpha particles, essentially all of which are emitted at grazing angles to the source, are not detected. The difficult problem of estimating the backscattering contribution is thus avoided.

The total efficiency for this geometry, $\varepsilon_{0}, 8 \pi$, of the counter was deduced from measurements on thin sources with the $2 \pi$ and $0.8 \pi$ counters for different values of atomic number, $Z$, of the backing material [9].

The $2 \pi$ count rate, $N_{2 \pi}$, divided by the $0.8 \pi$ count rate, $N_{0.8 \pi}$, was plotted as a function of $Z$, and extrapolated to $Z=0$ where, theoretically, $\varepsilon_{0.8 \pi}=N_{0.8 \pi} / 2 N_{2 \pi}=N_{0.8 \pi} / N_{0}$.

A schematic diagram of the spectrum for either the $2 \pi$ or $0.8 \pi$ counter is shown in Fig. 2. The multichannel analyzer is set to integrate counts above a level just above noise. The number of true counts in the noise region are estimated by means of an extrapolation of the flat part of the spectrum to zero pulse height.

5. General Operational Procedures

5.1. $2 \pi \alpha$ : After the source has been introduced into the counter and the sensitive volume flushed until the pulses observed on the pulse-height analyzer have reached their maximum height, the counting procedure is initiated. Typically, the counting proceeds in the order: background, standard reference source, submitted source, background. The counting times are adjusted so that $10^{6}$ counts from the source are collected (corresponding, of course, to 0.1 percent statistical uncertainty). These total counts are collected usually over five repetitions, or approximately $2 \times 10^{5}$ counts per measurement.

The functioning of the instrument is checked by comparing the measurement results for the standard, corrected for decay, and the background with previous results.

Five collection windows are set covering the lower end of the spectrum for the purpose of obtaining an extrapolation in the case where the total number of counts into $2 \pi$ are required. The extrapolation is based on the assumption that the "true" tail of the spectrum (Fig. 2) can be represented as a flat horizontal line with a height corresponding to the spectrum minimum.

In many cases, the customer asks not for total alpha-particle-emission rate into $2 \pi$, but instead, the rate for those emitted with energies above $400 \mathrm{keV}$. In this case, a rough energy calibration is performed using the $\alpha$-particle "peak" obtained at a lower known gain setting to avoid saturation as a reference (the $\alpha$ energies can be obtained from the Nuclear Data File). The spectrum above the $400 \mathrm{keV}$ point is integrated. In either case, background is subtracted and the result, reduced to counts per second, is entered onto the calibration certificate (Appendices $A$ and $B$ ). The random uncertainty is taken as the internal standard deviation of the mean of the five repetitions with a total of $10^{6}$ counts. The corresponding random uncertainty would 
be 0.1 percent if other components of variation are all zero. A comparison of the internal standard deviation and, in this case, 0.1 percent is referred to as the "index of dispersion" test. So-called systematic errors are estimated at the $1 \sigma$ level and are added in quadrature. In the example given in Appendix A, there are only two such components, the inaccuracies in the selection of the pulse height at $400 \mathrm{keV}$ and in the system dead time. When appropriate, uncertainty due to extrapolation of the a spectrum to zero energy should be taken into account. The overall uncertainty quoted in the certificate is three times the calculated combined uncertainty [13].

5.2. $0.8 \pi \alpha$ : Generally the same procedure for data collection and reduction is employed with the $0.8 \pi \alpha$ as with the $2 \pi \alpha$ counter. Only activity measurements are made with the $0.8 \pi$ counter, therefore all measurements involve extrapo1 ated values to which a calibration factor of $1 / \varepsilon_{0.8 \pi}=5.0638$ is applied (see reference 5). A sample certificate is shown in Appendix B. The one significant operational difference from the $2 \pi \alpha$ counter is that the correct source height must be determined by varying the vertical position of the source through screwing the mount in or out as required. The count rates will go through a maximum (as shown in Fig. 8 from [4]) representing the correct vertical setting.

\section{Step-by-Step Procedures ${ }^{4}$}

\section{SAFETY PRECAUTIONS}

The following procedures have been developed to ensure the safety of the operator. It is important that they be followed meticulously in the order given.

\subsection{Procedure for Using the $2 \pi \alpha$ Counter:}

- To Start

Turn on electronics (NIM BIN).

Turn on Air pressure valve (to raise and lower top of counter). Raise top of counter by pulling handle up slowly.

Place source in center of counter, handling the source with gloves to prevent possible contamination.

Lower top of counter by pulling handle down slowly.

Turn on gas ( $P-10$, Argon-Methane) at main valve and adjust diaphragm control to about 2-3 1 bs $/$ in $^{2}$.

Open black knob on regulator and flush rapidly for about 10 minutes.

Turn on high voltage, (+)1425 volts, at start of flushing.

\footnotetext{
${ }^{4}$ Assembled by P. A. Mullen.
} 
Reduce flow to approximately $60 \mathrm{cc} / \mathrm{min}$; observe flow rate on small flowmeter on top of counter.

Connect amplifier to oscilloscope and observe pulses, usually with coarse gain at 16.

Connect amplifier to analyzer (at attenuator box).

Adjust coarse gain first to 4 and estimate energy calibration (keV/ch), using approximate midpoint of peak area.

Set desired integrals on analyzer (see sample data sheet).

Set teletype keyboard to "data".

Turn on teletype punch.

Raise coarse gain to 16 and begin counting.

\section{- To Change Source}

Turn teletype punch to "off" and keyboard to "local."

Cut off high voltage by turning off switch (not by turning "pots" to zero).

Turn off gas flow at black knob.

Open counter by raising top slowly.

Remove source carefully.

Place next source in center of counter.

Lower top of counter slowly.

Turn on gas at black knob.

Continue as above.

\section{- To Shut Down}

Turn off electronics (high voltage at switch and NIM BIN).

Turn off gas (close black knob, main valve, and release the diaphragm control).

Remove source or blank carefully.

Turn off air pressure valve.

Turn off teletype.

Take smears of counter and immediate area and count at Health Physics. 


\subsection{Procedure for Operating the $0.8 \pi \alpha$ Defined-Solid-Angle Counter: \\ - To Start}

Turn on electronics (NIM BIN) and high voltage interlock box.

High voltage power supply switch must be off.

Remove lead from interlock to breechblock.

CAREFULLY remove breechblock (which is also source mount) by unscrewing it.

Be ready to support the block when it comes free.

Place source in center on top of block (spacers for sources of various diameters in drawer under counter).

Replace block and turn to stop position CAREFULLY. (Care should be taken not to advance source to the point of contact with the central baffle.)

Replace lead from interlock.

Turn on gas (hydrogen) at main valve and adjust diaphragm control to about $4 \mathrm{lbs} / \mathrm{in}^{2}$. (The gas is exhausted directly to the outside.)

Open black knob between regulator and flow meter and flush for about 10 minutes, at 3 L.P.M. as indicated on flow meter.

Turn on high voltage, (+)1500 volts, at start of flushing.

Reduce flow rate to about 0.5 L.P.M.; observe flow rate on $f 1$ ow meter.

Connect amplifier output to oscilloscope and observe pulses.

Connect amplifier output to analyzer at attenuator input; coarse gain $=4$, fine gain $=3.20$.

Set desired integrals on analyzer (see sample data sheet).

Set teletype keyboard to "data."

Turn on teletype punch.

Begin counting. 
- To Change Source

Turn teletype punch to "off" and keyboard to "local."

Turn off high voltage at on-off switch.

Turn off gas flow by closing black knob.

Remove interlock lead.

CAREFULLY unscrew and remove block; be prepared to support the weight of the block when it comes free.

Remove source.

Place next source in center of top of block.

Continue as above.

- To Shut Down

Turn off electronics (high voltage at switch and NIM BIN).

Turn off gas (close black knob, main valve, and release the diaphragm).

Remove interlock lead.

Remove source carefully.

Take smears of block and counter area and count at Health Physics.

Replace block and turn to stop position.

Turn off interlock control.

Turn off teletype.

- Source Position

Horizontal - The available spacers fit most source diameters that we encounter. For those sources of a different diameter, a new spacer can be made, or the source may be centered on the block and secured with a minimum of double-stick tape. The tape method is not recommended for thin source mounts such as thin platinum.

Vertical - The optimum vertical position for counting a source will vary with the thickness of the source mount, and the type of deposit

(electroplated, vacuum evaporation, or dried deposit). This position is determined by counting the source (or one of a batch of similar sources) at the "0" turns or stop position, which is the point at which the block is against the bottom of the counter. Then, count at each $1 / 4$ or $1 / 2$ turn down, to the point where the count obviously decreases. These measurements can be plotted as count-rate-vs-breechblock position, and the operating point selected. The position which is thus determined can then be used for sources of the same configuration. 


\section{Calibration Service Procedure}

\subsection{Customer Contact}

a. Give specifications for physical dimensions and activity limits (and fee).

b. Emphasize that source container must protect active area from contact with anything.

c. Request customer to specify on purchase order what type calibration, i.e., $2 \pi$ emission rate or activity.

d. Give time frame (do not promise what you cannot deliver).

e. Request any other useful information (user telephone number, etc.).

f. Request customer to call when ready to send sources.5

g. Give correct addresses - 1) shipping

2) mailing.

h. Send calibration booklet.

\subsection{General Procedure}

a. Submit completed NBS-364 to Heal th Physics for approval before arrival of material

b. Notify Dr. Roald Schrack of the arrival and departure of all plutonium and uranium.

c. Accept material from Health Physics.

d. Calibrate, calculate, and write report.

e. Complete any necessary forms $(64,77,796 \mathrm{~A}) .6$

f. Package material (in original container(s) if possible).

\subsection{Test Folders}

a. Request test folder from OPMS on receipt of material to be cal ibrated.

b. Note dates material received, returned.

${ }^{5}$ Shipments sometimes go astray (even after they arrive at NBS), so it is useful to know when they are shipped to NBS and try to follow up on them. ${ }^{6}$ Give information for $796 \mathrm{~A}$ to person typing shipping order. 
8. Uncertainty Components

The corrections and uncertainty components considered are given in Table 3.

Table 3. Listing of count rate correction factors and typical $1 \sigma$ uncertainties for $2 \pi$ and $0.8 \pi$ measurements.

\begin{tabular}{|c|c|c|c|c|}
\hline \multirow[b]{2}{*}{ Correction } & \multicolumn{2}{|c|}{$2 \pi$ Counter } & \multicolumn{2}{|c|}{$0.8 \pi$ Counter } \\
\hline & $\begin{array}{l}\text { Typical } \\
\text { Correction } \\
\text { Factor }\end{array}$ & $\begin{array}{c}\text { Typical } \\
\text { Uncertainty } \\
(\%) \\
1 \sigma\end{array}$ & $\begin{array}{c}\text { Typical } \\
\text { Correction } \\
\text { Factor }\end{array}$ & $\mid \begin{array}{c}\text { Typical } \\
\text { Uncertainty } \\
(\%) \\
1 \sigma\end{array}$ \\
\hline Counter geometry $(\Omega)$ & 2.000 & 0.05 & 40.000 & 0.05 \\
\hline $\begin{array}{l}\text { Extension and non- } \\
\text { uniformity of source (E) }\end{array}$ & 1.000 & 0.05 & 1.005 & 0.05 \\
\hline $\begin{array}{l}\text { Self-absorption and scattering } \\
\text { from source and support }\left(\mathrm{S}_{\mathrm{a}}\right)\end{array}$ & 1.100 & 0.5 & 1.000 & 0.05 \\
\hline Scattering off counter wall $\left(S_{C}\right)$ & & & 1.000 & 0.02 \\
\hline $\begin{array}{l}\text { Transmission through } \\
\text { collimator edge }\left(T_{C}\right)\end{array}$ & & & 1.000 & 0.02 \\
\hline Scattering in/on detector $\left(S_{D}\right)$ & 1.000 & 0.01 & 1.000 & 0.01 \\
\hline $\begin{array}{l}\text { Transmission through } \\
\text { detector (no count) }\left(T_{D}\right)\end{array}$ & 1.000 & 0.01 & 1.000 & 0.01 \\
\hline Background (B) & 0.999 & 0.01 & 0.990 & 0.01 \\
\hline Deadtime $(\mathrm{J})$ & 1.010 & 0.01 & 1.010 & 0.01 \\
\hline $\begin{array}{l}\text { Extrapolation to zero } \\
\text { pulse height }(x)\end{array}$ & 1.050 & 0.5 & 1.010 & 0.5 \\
\hline $\begin{array}{l}\text { Setting of } 400 \mathrm{keV} \\
\text { discrimination level (D) }\end{array}$ & 1.000 & 0.6 & & \\
\hline Counting Statistics & & 0.1 & 1.000 & 0.1 \\
\hline
\end{tabular}


Although this table lists typical uncertainties, one could, by using these numbers, derive typical total uncertainties for the various measurements by combining the relevant uncertainty components in quadrature and multiplying by an arbitrary factor of 3. The measurements and these "typical" uncertainties in percent are follows:

(i) $2 \pi$ count rate above $400 \mathrm{keV} \ldots \ldots . . \ldots 1 . . \ldots$

(ii) $2 \pi$ count rate extrapolated to zero energy $\ldots \ldots . . .1 .5$

(iii) activity derived from $2 \pi$ count rate extrapolated to zero energy and corrected by theoretical $2 \pi / N_{0}$ factor [8] . . 2.2

(iv) activity from $0.8 \pi \alpha$ measurements . . . . . . 1.6

In Table 3 typical corrections and uncertainties associated with the determination of alpha-particle activity are given. A source with a diameter of $4 \mathrm{~cm}$, a thickness equal to one fourth of the alpha-particle range, and an activity of $2000 \mathrm{~s}^{-1}$ is assumed. These uncertainties will vary in individual cases depending on such factors as source size, source uniformity, alpha-particle energy, impurities, interfering radiations and count rate to background ratio. Appendices $A$ and $B$ give examples of uncertainty computation in two specific cases. Uncertainties for other sample measurements will, in general, be different from these two examples but are nearly always within 0.5 percent in the quoted overall uncertainty. A number of the entries in Table 3 have been considered and evaluated but are normally negligible and are not included in the examples given in Appendices $A$ and $B$.

The uncertainty estimates are given at roughly the $1 \sigma$ level. For the most part the table is self explanatory. Symbols used in this section are identified in Table 3.

The measurement equation for the $2 \pi$ counter giving the count rate into $2 \pi, C_{2 \pi}$, in terms of the gross rate, $G_{2 \pi}$;

$$
C_{2 \pi}=\frac{\left(G_{2 \pi}-B_{2 \pi}\right)}{1-J}[X \text { or } D] S_{D} T_{D}
$$

(Note: If an estimate of activity is desired, the right hand side must be multiplied by $\Omega S_{a}$ and $X$ must be used.)

The measurement equation for the $0.8 \pi$ counter giving the total activity, $A$, in terms of the gross rate, $G_{0.8 \pi}$, is

$$
A=\frac{\left(G_{0.8 \pi}-B_{0.8 \pi}\right)}{(1-J)} \Omega E S_{a} S_{C} T_{C} S_{D} T_{D} X
$$

where the symbols are defined in Table 3. Now follow some notes on the sources of error:

8.1. Counter Geometry: The uncertainty in $\Omega(0.8 \pi)$ is estimated from possible differences between the calculated values, previously described, based on alternate extrapolations to $Z=0$. 
8.2. Extension and Non-Uniformity of Source: If the source is large enough, it witl impinge on the region of point-source position for which the response of the detector is significantly ( $>0.1$ percent) different from that at the center. These effects have been previously described in the Design Philosophly and Theory Section.

8.3. Self-Absorption and Scattering from Source and Support: This effect is very much larger for $2 \pi$ sources because, as previously pointed out, back and forward scattered particles involve those alphas which are coming off the source at grazing angles. For even moderately thick sources, this correction could be quite significant for $2 \pi$ sources yet be completely insignificant in $0.8 \pi$ geometry because the $0.8 \pi$ counter measures those forward directed, relatively scatter-free, particles. As discussed on page 6 under Scattering, the activity of an alpha-particle-emitting source can be obtained from the $2 \pi$ extrapolated $2 \pi$ counting rate using a theoretical $2 \pi / N_{0}$ counting rate [8].

8.4. Scattering off Counter Wall: This effect does not exist in the $2 \pi$ counter because alpha particles do not reach the wall. The dimensions of the $0.8 \pi$ counter are such that very rare large-angle scattering would be required to produce such events.

8.5. Transmission through Collimator Edge: This applies only to the $0.8 \pi$ counter and is negligible based on the range of alpha particles in the collimator material.

8.6. Scattering in/on Detector: This is a conceivable, but entirely negligible, effect for these counters as in the Transmission through Detector.

8.7. Background: This is not observed as being variable with time and could supposedly be driven down through collection of massive statistics. Generally, enough counts are accumulated to reduce the background uncertainty contribution to less than 0.1 percent.

8.8. Dead-time: The expression for dead-time correction is given in the measurement equations for uncompensated systems. However, the multichannel analyzer, which is the dominant source of dead-time losses, has a highly precise dead-time compensator so that for a one percent dead time correction, for example, the uncertainty due to this effect is entirely negligible.

8.9. Extrapolation to Zero Pulse Height: The shapes of the spectra in the low energy region have significant curvature. Consequently, an extrapolation based on the minimum value has significant uncertainty.

8.10 Setting of $400 \mathrm{keV}$ Discrimination Level: For $2 \pi$ calibrations for which the customer requests the $2 \pi$ emission rate above $400 \mathrm{keV}$, the discriminator setting at that level carries a significant degree of uncertainty. The reason for this is that the gain for a loop anode proportional counter is doublevalued because of the asymmetrical electric field lines in the counter. Thus any energy calibration will have some ambiguity and carries with it a relatively large uncertainty. 
8.11 Counting Statistics: The standard deviation of the mean of repeated counts is taken as the basic measure of statistical uncertainty.

The overall uncertainty is estimated by summing in quadrature, the standard errors of all calculated or estimated uncertainties and multiplying by a factor of three which then gives approximately a 99 percent confidence level.

\section{Quality Control}

The day-to-day control of the instruments uses a known standard which is measured at the time of a calibration.

Cross checks between the counters and other specialized counters such as the $0.1 \pi$ counter [4] are also performed. For example, a given calibration will be performed and a quick cross check of this source on another counter will be made. Such checks provide a feeling for the quality of source, a check on the functioning of the calibration counting system, and cross calibration in the (unlikely) event that questions are raised at a later date.

The only large international intercomparison of alpha-particle-emitting sources was performed under the sponsorship of the BIPM in 1963 on a solution of $241 \mathrm{Am}$. The agreement of NBS with the international average was in the 0.1 percent range. It was concluded at that time that the calibration of alpha-particle emitters was well understood and no futher international comparisons have been made on alpha-particle emitters. 


\section{REFERENCES}

1. NBS Special Publication 250, "NBS Calibration Services Users Guide 1986-88," G. A. Uriano, et al., Editors, U.S. Department of Commerce, National Bureau of Standards, U.S. Government Printing Office, Washinton, D.C. July 1986.

2. Walker, D.H. "an Experimental Study of the Backscattering of 5.3-MeV Alpha Particles from Platinum and Monel Metal", Int. J. Appl. Radiat. Isotopes, 16, 183 (1965).

3. NCRP Report 58, A Handbook of Radioactivity Measurements Procedures, Section 3.7 "Alpha Particle Counting", Mann, W.B. (ed) National Council on Radiation Protection and Measurements, Washington (1978).

4. The Standardization of Alpha-Particle Sources. L.L. Lucas. Proceedings of the ASTM Conference of Effluent and Environmental Radiation Surveillance, July 9-14, 1978, Johnson, Vermont, in ASTM Spec. Tech. Publ. 698. American Society for Testing and Materials (ASTM), pp. 342-354 (1980).

5. Temmer, G.M. and Wycoff, J.M., "Alpha-Ray Measurements Program" National Bureau of Standards, Report No. 2598, 1953.

6. Hawkings, R.C., Merritt, W.F., and Craven, J.H. in Recent Developments and Techniques in the Maintenance of Standards, Her Magesty's Stationary Office, London, 1952, p. 35.

7. Hutchinson, J.M.R., Lucas, L.L., Mullen, P.A. "Study of the Scattering Correction for Thick Uranium-0xide and Other a-Particle Soures-II: Experimental", Int. J. Appl. Radiat. Isotopes, 27, 43 (1976).

8. Lucas, L.L, and Hutchinson, J.M.R. "Study of the Scattering Correction for Thick Uranium-0xide and Other a-Particle Sources-I: Theoretical", Int. J. Appl. Radiat. Isotopes, 27, 35 (1976).

9. Hutchinson, J.M.R., Naas, C.R., Walker, D.H., Mann, W.B. "Backscattering of Alpha Particles from Thick Metal Backings as a Function of Atomic Weight", Int. J.Appl. Radiat. Isotopes, 19, 517 (1968).

10. Robinson, H.P. in Metrology of Radionuclides, International Atomic Energy Agency, Vienna, Austria, 1960, p. 147.

11. Jaffey, A.H., Flynn, K.F., Bentley, W.C., and Karttunen, J.0., Phys. Rev. C $\underline{9}, 1974$, p. 1991.

12. Bambynek, W.B. in Standardization of Radionuclides, International Atomic Energy Agency, Vienna, Austria, 1960, p. 147.

13. Giacomo, P. "News from BIPM, " Metrologia 17, 73 (1981). 


\title{
REPORT OF CALIBRATION
}

for

\author{
Bendix Field Engineering Corporation \\ Grand Junction Operations \\ Grand Janction, Colorado
}

Radionuclide

Source identification

Activity

Reference time

Half life

Overall ancertainty

Measuring instrument

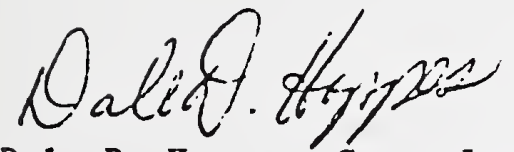

Dale D. Hoppes, Group Leader

Radioactivity Group

Center for Radiation Research
Americium-241 (1)*

$4904 M-F-79$

$1.528 \times 10^{2} \mathrm{~Bq}$

March 24, 1986

432.2 years

1.5 percent

$" 0.8 \pi " \alpha$ counter

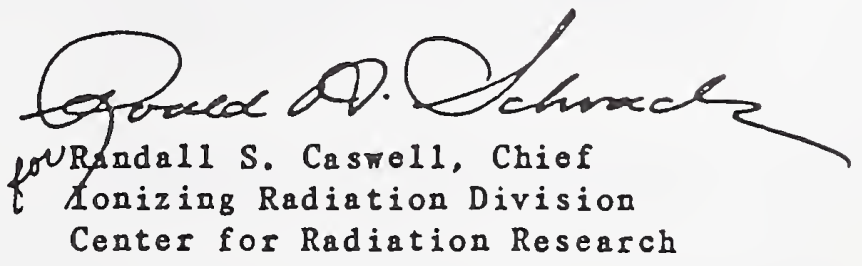

* Notes on next page

Gaithersbarg, MD 20899

March 31, 1986

NBS Test No. 236927 


\section{NOTES}

(1) This source was said by the castomer to be americium-241. No checks rere made for impurities at NBS.

(2) Including scattered alpha particles.

(3) From the Evaluated Nuclear Structure Data File, August, 1980. One mean tropical year $=365.2422 \mathrm{~d}$.

(4) The overall uncertainty is three times the value found from combining quadratically tho standard doviations of the mean, or approximations thereof, of the following:
a) one standard deviation of the mean of 10 measurements
0.07 percent
b) count rate extrapolation
to zero energy
0.50 percent
c) system live time
0.05 percent

(5) Defined-solid-angle counter with scintillation detector.

For further information contact J.M.R. Hatchinson or S.J. Walker at (301) 921-2396 or (FTS) 921-2396. 
Appendix B

U.S. DEPARTMENT OF COMMERCE

NATIONAL BUREAU OF STANOARDS

WASHINGTON, O.C. 20234

\title{
REPORT OF CALIBRATION
}

\author{
for \\ Department of the Air Force \\ HQ Aerospace Guidanco and Metrology Center \\ Newark Air Forco Station, Ohio
}

Radioneclide

Source identification

$2 \pi$ alpha-particle

counting rate

Reference time

Overall uncertainty

Measuring instrument

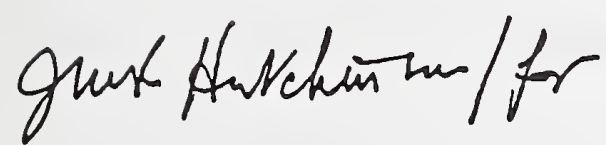

Dalo D. Hoppes, Group Leader Radioactivity Group

Center for Radiation Research
Plutonium-239

\#9 8-03 8-1

$214.0 \mathrm{~s}^{-1}(1) *$

December 30,1985

1.5 percent

NBS $2 \pi a$ proportional counter

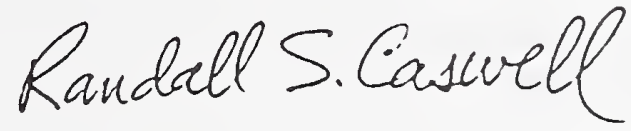

Randa11 S. Caste11, Chief Ionizing Radiation Division Center for Radiation Research

* Notes on next page 


\section{NOTES}

(1) The number of alpha particles with energies greater than 400 keV counted per second in a $2 \pi$-steradian geometry (including those scattered).

(2) The overall ancertainty is three times the value found from combining quadratically the standard deviations of the mean, or approximations thereof, of the following:
a) one standard deviation of the mean of 10 mea surements
0.1 percent
b) selection of polse height at $400 \mathrm{keV}$
0.5 percent
c) system 1 ive time
0.05 percent

For furtber information contact J.M.R. Hutchinson (301) 921-2396 or (FTS) 921-2396. 


\begin{tabular}{|c|c|c|c|}
\hline $\begin{array}{l}\text { U.s. DEPT. OF COMM. } \\
\text { BIBLIOGRAPHIC DATA } \\
\text { SHEET (See instructions) }\end{array}$ & $\begin{array}{l}\text { 1. PUBLICATION OR } \\
\text { REPORT NO. } \\
\text { NBS/SP-250/5 }\end{array}$ & 2. Performing Organ. Report No. & $\begin{array}{l}\text { 3. Publication Date } \\
\text { July } 1987\end{array}$ \\
\hline
\end{tabular}

4. TITLE AND SUBTITLE

NBS Measurement Services:

Alpha-Particle Calibrations

5. $A U T H O R(S)$

J.M.R. Hutchinson

6. PERFORMING ORGANIZATION (If joint or other than NBS, see instructions)

7. Contract Grant No.

NATIONAL BUREAU OF STANDARDS

U.S. DEPARTMENT OF COMMERCE

GAITHERSBURG, MD 20899

8. Type of Report \& Period Covered

Final

9. SPCNSCRHG ORCAHHZATHON NAME AND COMPLETE ADDRESS (Street, CITY, Stote, ZIF)

Same as item 6 .

10. SUPPLEMENTARY NOTES

Library of Congress Catalog Card Number: 87-619849

L Document describes a computer program; SF-185, FIPS Software Summary, is attached.

11. ABSTRACT (A 200-word or less factual summary of most significant information. If document includes a significant bibliography or literature survey. mention it here)

This document describes the alpha-particle calibration services offered by the Radioactivity Group of the National Bureau of Standards (NBS) (Scheduled Calibrations; 43030C and 43040C; formerly 8.2H and 8.2I). The fundamental measurement quantities are defined, the measurement approach is described (or reviewed), and the operating procedures are described from the point of view of the calibration technician or metrologist. The measurement uncertainties, and how they are estimated, are described. Methods for maintaining and assessing quality control, e.g., international comparisons, MQA programs, etc. are also briefly reviewed.

12. KEY WORDS (Six to twelve entries; alphabetical order; capitalize only proper names; and separate key words by semicalons) alpha particle; calibrations; counters; emission rate; radioactivity; standards

13. AVAILABILITY

[X] Unlimited

$\square$ For Official Distribution. Do Not Release to NTIS

$\mathrm{X}$ Order From Superintendent of Documents, U.S. Government Printing Office, Washington, DC 20402.

[] Order From National Technical Information Service (NTIS), Springfield, VA 22161
14. NO. OF

PRINTED PAGES

34

15. Price 



\section{PUBLICATIONS IN THE SP 250 SERIES FROM THE CENTER FOR RADIATION RESEARCH}

SP 250-1 NBS Measurement Services:

Spectral Radiance Calibrations

J.H. Walker, R.D. Saunders, and A.T. Hattenburg

SP 250-2 NBS Measurement Services:

Far Ultraviolet Detector Standards

L.R. Canfield and N. Swanson

SP 250-3 NBS Measurement Services:

Radiometric Standards in the Vacuum Ultraviolet J.Z. Klose, J.M. Bridges, and W.R. Ott

SP 250-4 NBS Measurement Services:

Fricke Dosimetry in High-

Energy Electron Beams

C.G. Soares, E.L. Bright and M. Ehrlich

SP 250-5 NBS Measurement Services:

Alpha-Particle Calibrations

J.M.R. Hutchinson

SP 250-6 NBS Measurement Services:

Regular Spectral Transmittance

K.L. Eckerle, J.J. Hsia, K.D. Mielenz, and V.R. Weidner

SP 250-7 NBS Measurement Services:

Radiance Temperature Calibrations

W.R. Waters, J.H. Walker, and A.T. Hattenburg

SP 250-8 NBS Measurement Services:

Spectral Reflect ance

V.R. Weidner and J.J. Hsia

SP 250-9 NBS Measurement Services:

Calibration of Beta-Particle-Emitting

Ophthalmic Applicators

J.S. Pruitt

SP 250-10 NBS Measurement Services:

Radioactivity Calibrations with the " $4 \pi$ "

Gama Ionization Chamber, and Other

Radioact ivity Calibration Capabilities

J.M. Calhoun

SP 250-11 NBS Measurement Services:

Dosimetry for High-Doce Applications

J.C. Humphreys, D. Hocken, and W.L. McLaughlin
SP 250-12 NBS Measurement Services: Neutron Personnel Dosimetry R.B. Schwartz

SP 250-13 NBS Measurement Services: Act ivation Foil Irradiation with Californium Fission Sources G.P. Lamaze and J.A. Grundl

SP 250-14 NBS Measurement Services:

Activation Foil Irradiation by Reactor Cavity Fission Sources

G.P. Lamaze and J.A. Grundl

SP 250-15 NBS Measurement Services: Photometric Calibrations

R.L. Booker and D.A. MCSparron

SP 250-16 NBS Measurement Services:

Calibration of X-Ray and Gamma-Ray

Measuring Instruments

P.J. Lamperti, T.P. Loftus, and R. Loevinger

SP 250-17 NBS Measurement Services:

The NBS Photodetector Spectral Response

Calibration Transfer Program

E.F. Za lewski

SP 250-18 NBS Measurement Services:

Neutron Source Strength Calibrations

E.D. McGarry and E.W. Boswell

SP 250-19 NBS Measurement Services:

Calibration of Gamma-Ray-Emitting

Brachyther apy Sources

J.T. Weaver, T.P. Loftus, and R, Loevinger

SP 250-20 NBS Measurement Services:

Spectral Irradiance Calibrations

J.H. Walker, R.D. Saunders, J.K. Jackson, and D.A. McSparron

SP 250-21 NBS Measurement Services:

Calibration of Beta-Particle

Radiation Instrumentation and Sources

J.S. Pruitt, C.G. Soares, and M. Ehrlich 
U.S. Department of Commerce National Bureau of Standards

Gaithersburg, MD 20899

Official Business

Penalty for Private Use $\$ 300$ 